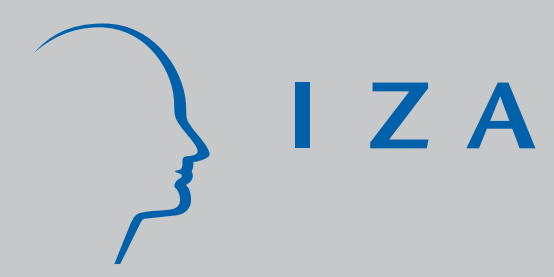

IZA DP No. 1951

Are the Factors Affecting Dropout Behavior Related to Initial Enrollment Intensity for College Undergraduates?

Leslie S. Stratton

Dennis M. O'Toole

J ames N. Wetzel

J anuary 2006 


\title{
Are the Factors Affecting Dropout Behavior Related to Initial Enrollment Intensity for College Undergraduates?
}

\author{
Leslie S. Stratton \\ Virginia Commonwealth University \\ and IZA Bonn \\ Dennis M. O'Toole \\ Virginia Commonwealth University \\ James N. Wetzel \\ Virginia Commonwealth University
}

Discussion Paper No. 1951

January 2006

IZA

P.O. Box 7240

53072 Bonn

Germany

Phone: +49-228-3894-0

Fax: +49-228-3894-180

Email: iza@iza.org

Any opinions expressed here are those of the author(s) and not those of the institute. Research disseminated by IZA may include views on policy, but the institute itself takes no institutional policy positions.

The Institute for the Study of Labor (IZA) in Bonn is a local and virtual international research center and a place of communication between science, politics and business. IZA is an independent nonprofit company supported by Deutsche Post World Net. The center is associated with the University of Bonn and offers a stimulating research environment through its research networks, research support, and visitors and doctoral programs. IZA engages in (i) original and internationally competitive research in all fields of labor economics, (ii) development of policy concepts, and (iii) dissemination of research results and concepts to the interested public.

IZA Discussion Papers often represent preliminary work and are circulated to encourage discussion. Citation of such a paper should account for its provisional character. A revised version may be available directly from the author. 


\title{
ABSTRACT \\ Are the Factors Affecting Dropout Behavior Related to Initial Enrollment Intensity for College Undergraduates?*
}

\begin{abstract}
We use data from the 1990/94 Beginning Post-Secondary Survey to determine whether the factors associated with long-term attrition from higher education differ for students who initially enrolled part-time as compared to for students who initially enrolled full-time. Using a two-stage sequential decision model to analyze the initial enrollment intensity decision jointly with attrition, we find no evidence of correlation in the unobservables that necessitates joint estimation, but substantial evidence that the factors associated with attrition differ by initial enrollment status. The timing of initial enrollment, academic performance, parental education, household characteristics, and economic factors had a substantially greater impact on those initially enrolled full-time, while racial and ethnic characteristics had a greater impact on those initially enrolled part-time. The results of our study suggest that separate specifications are necessary to identify at-risk full-time as compared with at-risk part-time students.
\end{abstract}

JEL Classification: $\quad 121$

Keywords: college enrollment, college dropout, part-time enrollment

Corresponding author:

Leslie S. Stratton

Department of Economics

Virginia Commonwealth University

1015 Floyd Avenue, PO Box 844000

Richmond, VA 23284-4000

USA

Email: Isstratt@vcu.edu

\footnotetext{
* The data employed here were generated while working under a grant supported in part by the Association for Institutional Research, the National Center for Education Statistics, and the National Science Foundation under the Association for Institutional Research 1999 Improving Institutional Research in Postsecondary Educational Institutions Grant Program. The Spencer Foundation Small Grants program provided funding for the analysis. Leslie Stratton gratefully acknowledges additional support from a 2001 Faculty Excellence Award from Virginia Commonwealth University. Referees from the 2005 Southern Economic Association meetings and from Research in Higher Education provided very helpful comments. Any opinions, findings, conclusions, or recommendations expressed in this material are those of the authors and do not necessarily reflect the views of the Spencer Foundation, the Association for Institutional Research, the National Center for Education Statistics, or the National Science Foundation.
} 


\section{Are the Factors Affecting Dropout Behavior Related to Initial Enrollment Intensity for College Undergraduates?}

\section{INTRODUCTION}

Our goal is to evaluate whether and, if so, how the factors affecting dropout behavior differ by initial enrollment intensity: part-time versus full-time status. Numerous researchers have examined the factors that affect college dropout rates for those initially enrolled full-time. However, as reported by Horn (1998) and Horn and Berger (2004), between twenty to thirty percent of all first-time undergraduates initially enroll as part-time students. While attrition rates are higher for part-time students, there has been little research explicitly comparing the reaction functions across these two student populations.

Our work differs from many earlier efforts in three substantial respects. First and foremost, we posit that the attrition behavior of different groups, in particular of part-time and full-time students, is likely to be affected by different underlying factors. Furthermore, the two groups may respond differently even to the same factors affecting attrition. This is analogous to the work in pharmacology which has moved from pooled studies to targeted research focusing on how different subsets of the population, such as men and women or those of Caucasian/European ancestry and those of African ancestry respond to the same treatment. There is a growing body of evidence that different populations not only may be affected by different diseases but, more importantly, react differently to the same drug regimen for a common disease. We employ a two-stage sequential decision model that allows the factors influencing the attrition decision to differ for part-time and full-time students. This specification also allows the unobservable 
factors influencing the enrollment intensity decision to be correlated with the unobservable factors influencing the attrition decision.

Second, this study focuses on dropout behavior from higher education in general. We use a national data set that enables us to distinguish between those students who drop out from one institution but transfer to another institution, and those students who drop out of higher education as a whole. From the standpoint of a single institution, transfer students are dropouts. From a national perspective, however, these transfers do remain enrolled in higher education.

Third, we recognize that many students who appear to be dropouts when using a single point-in-time measure of attrition, such as fall of their second year, actually reenroll soon thereafter and continue to pursue higher education. These individuals are not dropouts but stopouts. Recent work by Horn (1998), Horn and Berger (2004), Light (1996), as well as O’Toole, Stratton, and Wetzel (2003) discusses stopout behavior. Classifying temporary stopouts as long-term dropouts treats those who do continue their education, albeit in a discontinuous fashion, the same as those who permanently drop out. To avoid commingling stopout with dropout behavior, we first use longitudinal data to identify those who temporarily stop out and second, we treat stopouts as continuing students rather than as dropouts. Thus, we model long-term attrition in our analysis.

Separate analysis for full-time and part-time students permits us to evaluate underlying differences in the reaction functions of the two groups and thus shed greater light on the attrition decision. While part-time enrollment may be viewed as a "risk factor" in attrition studies, that approach does not provide much useful information from a policy perspective. Comparing the factors correlated with dropout behavior among part-time students with the factors correlated with dropout behavior among full-time students may lead to targeted policies that are more 
effective at increasing retention for both groups. To use the pharmacological analogy again, it is more useful to understand the reasons why African-Americans have higher blood pressure and how they react to high blood pressure medicines than it is to simply know they have higher blood pressure than those of Caucasian/European ancestry. In a similar fashion, it is more useful to know why or at least what factors are correlated with attrition for part-time students than to simply know that more of them drop out relative to full-time students.

\section{LITERATURE REVIEW}

There is a substantial literature on the attrition decision that incorporates both conceptual and empirical work. We first provide a brief overview of several of the conceptual models, including the work of Tinto (1975), Bean (1980), and Cabrera, Nora, and Castañeda (1993) from the education literature, as well as the work of Becker (1974), Light (1996), and Stratton, O’Toole, and Wetzel (2004) associated with the human capital literature from economics. These conceptual models help identify the factors likely associated with attrition to evaluate in empirical work. We follow the overview with a more detailed empirical discussion based on the human capital model.

Tinto formulated a Student Integration Model (1975) which has since been further developed (1988, 1993). In this model, the likelihood of an institution retaining an individual student is a function of the match between that student's academic ability and motivation or commitment and the school's academic and social characteristics. Tinto recognized the importance of evaluating the benefits and costs of education: "the model .... suggests that such evaluations will be reflected in the person's changing commitments to the goal of college completion” (1975, p. 98). The Student Integration Model “permits one to include the effects of 
changing supply and demand in the job market on rates of dropout.” (1975, p. 98). Bean’s Student Attrition Model (1980) stresses the role of behavioral intentions and financial factors on attrition. Cabrera, Nora, and Castañeda (1993) combined elements from Tinto and Bean into an Integrated Model of Student Retention.

Becker's approach, to human capital formation in general and educational achievement specifically, explicitly incorporates all factors judged to affect either the costs or the benefits of the decision. According to a human capital model of attrition, students will remain enrolled in college as long as the present value of expected benefits exceeds the present value of expected costs (PVB>PVC). There are both financial and non-financial benefits and costs associated with pursuit of a degree. The major financial benefit of staying in school is the higher future income expected after graduation. Non-financial benefits may include a more satisfying job, better working conditions, and opportunities to meet members of a desired peer group. Financial costs include factors such as tuition and forgone earnings. Non-financial costs may include other opportunity costs associated with time in school, and the psychic costs of studying.

\section{A Human Capital Model of Attrition}

The human capital model we employ provides an explicit rationale to recognize and incorporate factors that affect either the costs or the benefits of attrition. Many of these factors are tested in the empirical education literature. Demographic characteristics such as gender, race, ethnicity, and age are often included as "control variables". The human capital model justifies their inclusion on the basis that the rates of return to education may differ for different demographic groups. Altonji (1993), for example, found evidence that women receive a higher return to education than men. Age enters the benefit-cost calculations in the human capital model directly. Starting college at a later age decreases the present value of expected financial 
and non-financial benefits since the time period for future earnings will be shorter than that for a younger person. Costs may also be higher if opportunity costs increase with age. Horn’s (1998) finding that older students were more likely to drop out supports our hypothesis that older students have a lower net benefit of attendance.

In the human capital model, higher family income and the availability of financial aid serve to reduce the financial burden on the cost side of the model. The type of financial aid is also important, as loans require a future repayment while grant aid does not. Financial aid variables are important factors in the education literature, and there is ample empirical evidence of their relation to attrition (see for example, St. John, Hu, \& Weber 2001, St. John \& Starkey 1995) as well as evidence that different types of aid have differential affects on attrition (DesJardins, Ahlburg, McCall 1999). Parental education measures may be utilized as a proxy for income, when household income data are not available. Above and beyond its relationship to income, parental education may play a role as indicative of family emotional or psychological support for higher education and familial expectations. Such expectations raise the costs associated with dropping out. Some evidence of this type of effect is reported by Ishitani (2003) and Ishitani and DesJardins (2002/2003), who found that even controlling for income, those with less educated parents have higher rates of attrition than those with college educated parents. There is also a possibility that first generation college students receive a lower return for their degree (Thomas and Zhang 2005).

Other relevant factors that impact benefits or costs include proximity measures, local economic conditions, and the student's own familial obligations. The distance a student must travel to attend college will influence the cost of attendance (Hoenack and Weiler 1975). Lower local unemployment rates and higher earnings possibilities increase the opportunity costs 
associated with college enrollment and serve to discourage enrollment, as discussed by Light (1996). Opportunity costs may also vary with marital and parental status. Horn (1998) found that individuals with children are more likely to drop out than those without children, while DesJardins, McCall, Ahlburg, and Moye (2002) found that parents are much less likely to graduate. The non-market based opportunity costs of enrollment are likely to be higher for those with children in the home. These costs may differ for men and women as the burdens of childcare are not as yet typically shared equally within the household.

Variables reflecting behavioral intentions and institutional characteristics are often incorporated in attrition models. The former are central to Bean's attrition model and the latter to Tinto’s integration model, as Bean emphasized the role of intentions and Tinto the individual/institution match. From the human capital perspective, intentions may reflect the degree to which benefits are perceived to be greater than costs, and institutional ties and characteristics are likely associated with the costs of attendance. Ishitani and DesJardins (2002/2003) found both educational aspirations and institutional characteristics to be significant determinants of attrition.

The absolute level of net benefits to enrollment matters in the attrition decision, since the smaller the level of net benefits, the more likely a change in circumstances will cause an individual to drop out. A student who perceives a very high net benefit to education will continue even if the costs increase substantially. Conversely, a student who perceives he or she is receiving only a small net benefit is more likely to drop out if benefits decline or costs increase only a small amount.

Reevaluation of both expected benefits and expected costs occurs in the face of information received after the date of initial enrollment. One of the most important pieces of 
new information for college students has to do with their academic performance. First year college grades are likely to be a better indicator to the student than either high school grades or standardized test scores, of the likelihood that he or she will complete a program of study. College GPA provides information concerning actual performance which more directly influences the probability of receiving the benefits of higher education. Bean (1980), Bean and Metzner, (1985), Murtaugh, Burns and Schuster (1999), and Harmston (2004) among others have discussed the importance of college GPA in the attrition decision.

The degree to which a student develops ties or becomes integrated to either a specific institution or to the higher education experience may also impact attrition. Learning how to operate in a new environment and establishing social and academic contacts during the first year reduces the psychic costs of continued enrollment. This is a critical component of Tinto's Student Integration model (1975). Such ties can only be established following enrollment and hence also constitute ‘new' information.

Other factors, which can vary over time, include marital status and parental status. Getting married or having a child is likely to significantly affect one's household responsibilities and one's opportunity cost of time. Some individuals facing a higher opportunity cost of time will rationally choose to leave higher education. Adelman (1999) reported that individuals who become parents are more likely to drop out. Given social norms, this affect is likely to differ for men and women. The human capital model easily incorporates new information concerning college grades, college ties or integration measures, and changes in marital and parental status as potentially important determinants of attrition through their influence on either the benefits or costs of attrition. 
Another variable sometimes included in attrition studies is a dummy variable indicating part-time status. Enrollment intensity could be thought of as an indicator of behavioral intentions and may be viewed as a risk factor for attrition (Montmarquette, Mahseredjian, and Houle 2001; Bradburn 2002). However, it is also reasonable to suppose that the factors influencing attrition through the benefit and cost calculations may differ by enrollment intensity. Institutional characteristics may have a differential impact by enrollment intensity as some institutions accommodate part-time students more readily than others. Residential "flagship" universities may be less supportive of, or even discourage, part-time students compared to urbanbased institutions that have larger numbers of part-time and working students. If students enrolled part-time are more active in the labor market, economic conditions may have a different effect on attrition for full-time as opposed to part-time students. College grades may also have a differential effect. Since students enrolled part-time accrue fewer credit hours than those enrolled full-time, the information conveyed by first year grades regarding the probability of graduation may be less valuable for part-time as compared to full-time students. The influence of changes in marital or parental status may also differ by full-time/part-time enrollment intensity. Such changes may be less likely to induce attrition among those enrolled part-time because part-time students are operating with a reduced course load.

If it is true that part-time and full-time students respond to different factors or respond differently to the same factors in deciding whether to drop out, then separate analysis of parttime and full-time students is necessary. If the initial enrollment intensity decision is itself related to the subsequent attrition decision, then joint modeling of the intensity and attrition decisions may be necessary. Some students may enroll part-time because they are particularly uncertain whether they can complete a degree and part-time enrollment is less expensive than 
full-time enrollment. If this uncertainty is not reflected in other observable factors, then it will be captured in the error component of the statistical analysis. Individuals who are more likely to enroll part-time for unobserved reasons may also be more likely to drop out for unobserved reasons. These concerns need to be addressed in empirical modeling and require estimation of a model of initial enrollment intensity.

Stratton, O’Toole, and Wetzel (2004) derived just such a model based on human capital theory. Their empirical model included a variety of factors known prior to initial enrollment as explanatory variables. Of particular interest, they found that part-time enrollment was more common for men than for women, for Hispanics than non-Hispanics, for older than for younger persons. Individuals who believed they were of average or lower mathematical ability, who lived in states with lower unemployment rates, and whose parents had less than a college degree were also more likely to enroll part-time. Marital and parental status were significant, too.

\section{EMPIRICAL SPECIFICATION}

The college attrition decision is typically modeled using a binary choice specification in which those who are not enrolled in a particular term are compared to those who are. The factors (X) associated with attrition (Dropout) are then identified by estimating a model of the following form, where the subscript i refers to the individual:

\section{(A) Dropout $_{\mathrm{i}}=\mathrm{X}_{\mathrm{i}} \beta_{\mathrm{A}}+\varepsilon_{\mathrm{iA}}$}

Particularly pertinent to this analysis is the treatment of part-time students. Many different approaches have been employed. For example, St. John, Hu, and Weber (2001) focused on only full-time undergraduates, while Starkey (1994) focused on only part-time students. Others have included both populations in their analysis and either not distinguished 
between them (Nora 1987) or used a dummy variable to identify those enrolled part-time (Montmarquette, Mahseredjian, and Houle 2001; Bradburn 2002). We recognize the pioneering approach of Weiler and Pierro (1988), who posited that enrollment intensity (full-time/part-time status) might be related to attrition not causally or simultaneously but because some of the same unmeasured factors influence both. They estimated a two equation probit model of the following form:

(B1) $\quad \mathrm{PT}_{\mathrm{i}}=\mathrm{Z}_{\mathrm{i}} \gamma_{\mathrm{B}}+\mu_{\mathrm{iB}}$

(B2) Dropout $_{\mathrm{i}}=\lambda \mathrm{PT}_{\mathrm{i}}+\mathrm{X}_{\mathrm{i}} \beta+\varepsilon_{\mathrm{BB}}$

(see Maddala 1989, section 5-7). The first equation models the decision to enroll part-time as a function of factors known prior to enrollment (Z). The second equation models the attrition decision as a function of factors (X) and of enrollment intensity (PT). For identification of the two equation model, $\mathrm{Z}$ must include some variables not also in $\mathrm{X}$. Estimates of $\lambda$, the relation between enrollment intensity and attrition, will be biased if equation B2 is estimated independently of B1 and $\mu_{\mathrm{B}}$ and $\varepsilon_{\mathrm{B}}$ are correlated. In fact, Weiler and Pierro found the correlation between $\mu_{\mathrm{B}}$ and $\varepsilon_{\mathrm{B}}$ to be positive and statistically significant, and to account for all of the heretofore estimated positive relation between part-time enrollment and attrition.

We adopt an alternative formulation, a two-stage sequential decision model described by Maddala (1989, section 8.3) as a switching regression. This specification differs substantially from Weiler and Pierro's approach. The equation representing the first stage decision (C1), like (B1), models the decision to enroll part-time. The second stage decision is the attrition decision, but this decision is allowed to differ depending upon the first stage outcome. Thus, equation C2 models the decision to drop out conditional upon enrolling full-time, and equation C3 models the decision to drop out conditional upon enrolling part-time. 
(C1) $\quad \mathrm{PT}_{\mathrm{i}}=\mathrm{Z}_{\mathrm{i}} \gamma_{\mathrm{C}}+\mu_{\mathrm{iC}}$

(C2) Dropout $_{\mathrm{i}}=\mathrm{X}_{\mathrm{i}} \beta_{\mathrm{F}}+\varepsilon_{\mathrm{iF}} \quad$ if enrolled full-time $\left(\mu_{\mathrm{iC}} \leq-\mathrm{Z}_{\mathrm{i}} \gamma_{\mathrm{C}}\right)$

(C3) Dropout $_{i}=X_{i} \beta_{P}+\varepsilon_{i P} \quad$ if enrolled part-time $\left(\mu_{i C}>-Z_{i} \gamma_{C}\right)$

Given three separate residuals, we assume that $\left(\mu_{\mathrm{C}}, \varepsilon_{\mathrm{F}}, \varepsilon_{\mathrm{P}}\right)$ have a trivariate normal distribution with mean vector zero and covariance matrix:

$\Omega=\left[\begin{array}{ccc}\sigma_{\mu}^{2} & \sigma_{\mu F} & \sigma_{\mu P} \\ & \sigma_{F}^{2} & \sigma_{F P} \\ & & \sigma_{P}^{2}\end{array}\right]$

The binary nature of the dependent variables necessitates normalizing all the diagonal terms to one. The fact that the decision to drop out is not observed for the same individual both when enrolled part-time and when enrolled full-time leaves $\sigma_{\mathrm{FP}}$ unidentified. However, the two remaining correlation terms, $\sigma_{\mu \mathrm{F}}$ and $\sigma_{\mu \mathrm{P}}$, are estimable. Should $\sigma_{\mu \mathrm{F}}\left(\sigma_{\mu \mathrm{P}}\right)$ equal zero, then consistent estimates of $\beta_{\mathrm{F}}\left(\beta_{\mathrm{P}}\right)$ can be obtained by estimating equation $\mathrm{C} 2$ (C3) directly without controlling for initial enrollment intensity (C1). However, if one of these correlations is not zero, then ordinary least squares estimation of the corresponding attrition equation will yield biased coefficient estimates because such estimation fails to take into account the knowledge of $\mu$ acquired from observation of PT.

Like Weiler and Pierro’s specification, our approach permits the unobserved factors influencing the enrollment intensity decision to be correlated with the unobserved factors influencing the attrition decision. However, our specification updates Weiler and Pierro's in two important respects. First, this specification allows the correlation to differ by initial enrollment intensity: $\sigma_{\mu \mathrm{F}}$ and $\sigma_{\mu \mathrm{P}}$ are estimated separately. Second, while Weiler and Pierro's formulation of the attrition model allows the initial enrollment intensity to affect only the intercept term in their 
attrition model, here initial enrollment intensity is further allowed to alter the slope parameters.

Thus, our specification permits part-time students to react to different factors or to react differently to the same factors as compared to full-time students when deciding whether to continue with their studies. ${ }^{1}$

Our analysis also differs from almost all prior research in our definition of attrition. First, given our focus on attrition from higher education as a whole rather than from a particular institution, we treat students who drop out of one institution but transfer to another as continuing students. This necessitates use of a longitudinal data set that follows individuals rather than tracks enrollment at a single institution. Second, we define attrition based on nonenrollment over a period longer than the standard single point-in-time definition of attrition, in order to distinguish between long-term dropout and short-term stopout behavior. This incorporates the finding reported by Horn (1998) that about half of those students who leave before the start of their second year return within a five year span, as well as the results of Stratton, O’Toole, and Wetzel (2005) that the factors related to dropout differ from the factors related to stopout. We are not the first to define attrition over a multiterm span. Bradburn (2002), for example, defined attrition as nonenrollment during the entire second year and Harmston (2004) defined attrition as nonenrollment one calendar year following matriculation (so that persistence is continuous enrollment for over one calendar year).

\footnotetext{
${ }^{1}$ An alternative literature uses hazard models to examine enrollment (as for example DesJardin, Ahlburg, and McCall 2002). These models do an excellent job modeling enrollment duration, but because they follow many individuals well beyond their first year, a hazard model would likely have to address changes in enrollment intensity. By focusing only on the first year, we limit the opportunity to change enrollment intensity and focus on the period when most attrition occurs.
} 


\section{DATA}

We estimate the model using data from the 1990/94 Beginning Post-Secondary Survey (BPS) available from the National Center for Education Statistics (NCES). This is a national data set that follows a stratified random sample of individuals from first enrollment in 1989-90 to 1992 or 1994. The stratified nature of the sample (institution type is selected first, then institution, then respondent) may introduce correlation in the errors (for example, across individuals enrolled at the same institution). We correct for such correlation in the analysis that follows (see Thomas and Heck 2001 for a discussion). The survey's focus on the individual rather than the institution allows us to follow respondents regardless of the institution attended or their enrollment status. Thus, we can focus on attrition from higher education and distinguish long-term from short-term attrition. As the BPS data set is not restricted by age, it includes a significant fraction of part-time students, a necessity for our joint analysis of attrition and enrollment intensity.

Only individuals who were interested in pursuing an academic degree (at the Associate or Bachelor's level) and attended institutions that were likely to provide credit toward such a program were included in our estimation sample. This eliminated from the sample many individuals pursuing a vocational education that might readily be completed within one calendar year, who we might otherwise classify as having dropped out because they will not be enrolled in the second year. Additional information on construction of the data set is available from the authors upon request. Note, however, that access to the raw data is restricted and available only from the NCES. Our final sample consists of 4655 individuals, 349 of whom were initially enrolled part-time. 
Enrollment intensity is determined based on first term enrollment data. We recognize that some individuals do change enrollment intensity over the course of their undergraduate years, but by focusing on the first calendar year we limit the opportunities for such change.

We define dropouts as individuals who are not enrolled in the term one calendar year after initial enrollment (usually fall 1990, but possibly as late as spring 1991) and who furthermore remain out of school through spring 1992. Spring 1992 coincides with the first BPS follow-up and constitutes a reasonable period to qualify as a long-term withdrawal. By this definition, about $40 \%$ of those not enrolled in the first term, one calendar year after matriculation were actually temporary stopouts - individuals who reenrolled some subsequent term prior to the summer of 1992 - rather than long term dropouts. These individuals are classified for this research as persisting since they do continue their education. In fact, over $75 \%$ of these respondents (those observed stopping out) complete at least two more terms prior to 1994, as compared with only about $5 \%$ of those classified here as dropouts. Thus, our 1992-based definition does a good job of distinguishing between stopout and dropout behavior in the even longer run. When dropout is defined instead as non-enrollment through the final 1994 interview date, we obtain similar results. We focus here on the 1992 rather than 1994-based dropout measure, in part, because of the smaller size of the 1994 sample and, in part, because given more time students are more likely to change their initial enrollment status (full-time/part-time) and we do not model such changes.

By focusing on long-term attrition from higher education, our measure of attrition differs substantially from those generally presented in the literature. The National Center for Higher Education Management Systems (2005) reports that of first-time, full-time students entering in the fall 1999 term, 32\% fail to return to the same institution the following fall. Using a 
comparable definition, we find an attrition rate of 33.9\% within the 1989-90 BPS. However, about $40 \%$ of those full-time students who do not return to the institution they first attended, were enrolled at a different institution. By our measure, $13 \%$ of all first-time, full-time students (including those beginning in the spring term) and $37 \%$ of all first-time, part-time students drop out for the long-term from all institutions of higher education. These measures are about half of those calculated using the institution-specific and point-in-time definition typically used.

The BPS survey includes a wide array of information, on both the respondents and the institutions they attended. This information enables us to model the enrollment intensity and attrition decisions. We added data indicative of the economic conditions and opportunities faced by the respondents to the BPS survey. Data obtained from the Bureau of Labor Statistics on the 1989 unemployment rate in the respondent's reported home state was incorporated to capture potential employment opportunities. Data on the mean annual earnings for high school graduates employed full-time, full-year were obtained from the 1990 Census and matched based on the age, gender, race, and ethnicity of the respondent. We used this measure to proxy for current earnings potential.

We adopt a specification of the initial enrollment intensity equation (C1) that is similar to the one employed by Stratton, O’Toole, and Wetzel (2004) in their analysis of initial enrollment status. Dummy variables for gender, race (Black, NonWhite/NonBlack), Hispanic ethnicity, highest level of parental education (Less than high school, High school, Some college, and Missing - College is the base case), and for gender-specific marital and parental status at the date of initial enrollment are included. Household income is incorporated by identifying those who were financially independent of their parents with one dummy variable and splitting those classified as financial dependents into four categories depending upon categorical parental 
income information: less than $\$ 20,000$, $\$ 20-30,000, \$ 30-50,000$, and over $\$ 50,000$. Those dependents whose parents earned between $\$ 30,000$ and $\$ 50,000$ form the base case to which all other populations are compared. Limiting the sample to those individuals pursuing an academic degree already restricts the behavioral intentions of the sample, but we include dummy variables to identify students who enrolled in the fall term as well as students who enrolled the term immediately following high school graduation, since these variables may be correlated with the degree of forethought and hence of interest in higher education (see Horn 1998, p. 24 for a discussion). As the BPS data does not include high school performance measures and standardized test scores are not available for many respondents, self-reported math ability and receipt of a high school diploma are incorporated as measures of pre-collegiate academic ability. The local unemployment rate and a measure of individual earnings potential are added to capture economic opportunity costs. Gender-specific, quadratic age measures and the number of preschool aged children are added to capture other types of opportunity costs.

In order to estimate a sequential decision model without relying only on functional form assumptions for identification, some variable(s) incorporated in the initial enrollment intensity equation must be excluded from the attrition equations (Maddala 1989). Weiler and Pierro (1988) use gender, age, and proximity to the school to uniquely identify enrollment intensity. We choose to include gender and age in our attrition equations as well as in the initial enrollment equations. We include institution-specific characteristics only in the attrition model, as such information is available only after the initial enrollment decision has been made (i.e. only after stage one is decided). We use self-reported math ability, receipt of a high school diploma, the number of preschool aged children, and the quadratic age measures to identify initial enrollment intensity. While identification of the sequential decision model is less dependent upon these 
exclusion restrictions than was Weiler and Pierro's model, we present evidence below of the robustness of our results to alternative specifications of our first stage equation.

Our attrition equations include all the remaining variables from the intensity model as well as additional data available post-enrollment. This additional data includes measures of first year academic performance, institution-specific information, financial aid receipt data, and changes in household status. To capture academic performance, we used the respondent's first year GPA. We chose to use institution-reported GPA measures when available, filling in missing values with self-reported grades. As the student-reported grades were categorical in nature, we employed the same categories for both self-reported and institution-reported GPAs. The base case to which all respondents were compared is that of an institution-reported GPA of between 2.25 and 3.25 (C to B). Students with higher institution-reported GPAs were denoted 'High Grade’ students. Students with lower institution-reported GPAs were denoted 'Low Grade’ students. When institution-reported data were not available and individuals self-reported grades of “As and Bs” or better, they were designated 'High Grade’ students. Those selfreporting grades of “mostly Cs” or worse were designated 'Low Grade’ students. Those selfreporting grades of "mostly Bs" or "Bs and Cs” were separately identified as ‘Self-Reported Average Grade’ students. This permits the impact of self-reported and institution-reported grades to be distinct for this middle grade range to reflect the inflationary impact of self-reported grades in this range. Several alternative specifications were tested, but this specification appeared to provide the best fit. $^{2}$

${ }^{2}$ In particular we tested the hypothesis that we could merge together self-reported and institution-reported 'High' and 'Low Grades'. We were unable to reject this hypothesis at even a 25\% significance level. 
Information about the first institution attended was used to construct the institutionspecific variables. These included dummy variables to identify public (as opposed to private) institutions, two-year (as opposed to four-year) institutions, and distance from the respondent's home to the institution. Following the earlier persistence literature, we also included measures of the respondent's 'attachment' to the institution. These measures of institutional fit were based on responses during the first year interview, with separate measures constructed for social and academic congruence. Dummy variables for both high and low levels of integration were created, leaving average levels of integration as the base case. Financial aid receipt is captured as a set of dummy variables to identify the type of financial aid (if any) each respondent received during the 1989-90 academic year: grant, loan, work-study, employer provided, or other.

Finally, we constructed dummy variables to identify those who became a parent within 18 months following initial matriculation and those who married within 15 months following initial matriculation. These variables were constructed in such a way as to focus on changes occurring between the date of initial enrollment and the term one calendar year later, assuming that individuals have some foresight regarding household changes.

Table 1 shows sample means for those persisting and dropping out by initial enrollment status. Included in the table are all the explanatory variables used in estimating the attrition models. Means that are statistically significantly different for those persisting and dropping out are identified with asterisks $\left(^{*}\right)$ separately by initial enrollment status. Differences in sample mean characteristics by initial enrollment status are identified with pound signs (\#). 


\section{RESULTS}

\section{Specification Issues}

We approach the sequential, binary choice model described above in two parts, first estimating equations $\mathrm{C} 1$ and $\mathrm{C} 2$ simultaneously to examine attrition amongst those initially enrolled full-time and then estimating equations C1 and C3 simultaneously to examine attrition amongst those initially enrolled part-time. This approach necessitates estimation of the first stage equation modeling initial enrollment intensity (C1) twice, but permits us to correct standard errors for the complex sample design. Estimates of both first stage equations for initial enrollment intensity (C1) are similar to those reported by Stratton, O’Toole, and Wetzel (2004) and are available upon request. Older individuals (especially men), those who delayed matriculation or initially enrolled in the winter or spring term, those whose parents have less formal education, those who were married, and Hispanics were more likely to enroll part-time.

Most important, the estimated correlation terms $\left(\sigma_{\mu \mathrm{F}}\right.$ and $\left.\sigma_{\mu \mathrm{P}}\right)$ are not statistically significantly different from zero, even at the $10 \%$ level. These results are robust to a number of specification tests. First, the variables used to identify enrollment intensity (i.e. the variables included in the first but not the second stage equations: self-reported mathematical ability, quadratics in age for men and women, and the dummy variable identifying individuals holding a high school diploma) are jointly statistically significant at the $4 \%$ level in the equation modeling initial enrollment intensity (C1) when examining attrition by part-time students. The same variables are jointly statistically significant at the $1 \%$ level in the equation modeling initial enrollment intensity (C1) when examining attrition by full-time students. The coefficients to these variables in the first stage equation indicate that students with higher self-reported math ability as well as those with a high school diploma are more likely to enroll full-time, and that 
the probability of enrolling full-time rises with age, but at a decreasing rate. It is important for these variables to have power in order to identify the coefficients at each stage without relying exclusively on distributional assumptions. Small sample sizes make additional tests on the parttime sample difficult, as collinearity amongst the variables becomes an issue and it becomes difficult to estimate any parameters precisely.

Additional tests on the specification modeling attrition by full-time students indicate that the exclusion restrictions are valid and that the correlation term remains statistically insignificant when alternative specifications are estimated. Thus, we explored specifications excluding some or all of the variables unique to the first equation and tested the exclusion restrictions we imposed by including these unique variables in the attrition equation. In no case, did we find that the exclusion restrictions were unwarranted; the variables unique to the first equation (C1) are not significant determinants of attrition (i.e. do not belong in equation C3). This is an important consideration because imposing faulty exclusion restrictions could result in spurious correlation measures. In every specification we tested, the correlation term is negative (indicating that those more likely to enroll full-time for unobserved reasons are more likely to persist for unobserved reasons) but statistically insignificant at a $20 \%$ or higher significance level.

Given that the initial enrollment intensity decision is not correlated in the unobservables with the subsequent attrition decision, it is not necessary to model these decisions simultaneously. Thus, we can estimate stand-alone second stage attrition models (C2 and C3). We do so using a logit specification, in conformity with much of the attrition literature.

The next key specification issue is whether attrition needs to be modeled separately by initial enrollment status using two equations or whether it is sufficient to estimate a single 
attrition model, perhaps with a dummy variable to identify part-time students. We use a Chow test (a standard parameter constancy test) to formally investigate this possibility. The results, even allowing for a separate intercept for part-time students, permit us to soundly reject the hypothesis that $\beta_{\mathrm{P}}=\beta_{\mathrm{F}}$ (p-value 0.0000). Separate equations provide a much better fit than would a single equation.

The odds ratios for the separate attrition models (C2 and C3) are reported in Table 2. Column one contains the ratios for those initially enrolled full-time and column two contains the ratios for those initially enrolled part-time. First, we focus on the results for those students enrolled full-time and second, we discuss how the results for part-time students differ from the results for full-time students.

\section{Attrition by Full-Time Students}

Attrition amongst full-time students follows patterns predicted by the theoretical literature and observed by previous researchers. Students coming from households with less educated parents were significantly more likely to drop out. For example, those whose parents

had completed high school or less were over twice as likely (odds ratio of 2.2) to drop out rather than continue as compared with students who have a college educated parent. Likewise, dependent students coming from households with annual incomes below \$20,000 had almost twice (1.8) as high a ratio of dropping out to continuing as compared to dependent students coming from households with annual incomes between \$30 and \$50 thousand dollars. Parental financial and psychological support for college is an important determinant of attrition for fulltime students.

Gender, age, and enrollment timing also influence the attrition rate. Several alternative gender-specific nonlinear age specifications were tested, but the gender-specific linear 
specification reported here provided the best and most parsimonious fit. This specification suggests that women have a higher probability of dropping out than men, but that age has a positive effect on men's probability of dropping out and a negative effect on women's. In fact, evaluated at age 18, there are no gender-specific differences in attrition rates. Such differences arise only for older individuals. These gender differences may be driven by the fact that women are more likely to interrupt their labor market experience in response to household responsibilities (marriage and childbirth). Women may rationally choose to delay acquiring education, particularly if they perceive education depreciating in value or becoming obsolete with the passage of time. Thus, delayed enrollment may be a planned event for women seeking to enter or reenter the labor market after some time spent raising children. These older women anticipated a later start to their post-secondary education, and that may explain why older women have a lower attrition rate than older men. However, both men and women who started in the fall term or matriculated immediately after high school have a much lower odds ratio (dropout relative to continuing) than those who delayed college entrance - about half as great. As discussed earlier, these variables may reflect, in part, the individuals' commitment to and interest in pursuing a college degree.

Household composition, as expected, has some association with attrition. Individuals who were married at the time of initial enrollment were not more likely to drop out than those who had never been married. However, both women and especially men who got married while in college were significantly more likely to drop out. For men, neither the presence of, nor the addition of a child to the household, has a significant impact on attrition rates - possibly because historically women have been the primary caregivers. For women, both the presence of a child 
at the time of matriculation and the arrival of one afterwards are associated with higher attrition rates.

Given the small number of respondents for whom marital status or household composition changed, we urge caution in the interpretation of these results. Furthermore, "household characteristics" constitute an area in which policy makers have relatively little influence, as the decision to marry or to have a child is generally outside the sphere of influence of educational advisors. Any impact a policy decision, such as providing free and high quality day care services, might have would be indirect. Such services would lower the opportunity cost of giving birth while enrolled as a student and likely reduce dropout rates for parents.

As expected, because of its importance in providing information regarding the probability of achieving a college degree, academic performance during the first year is both significantly and substantially associated with attrition. Those with higher grades were more likely to persist; those with lower grades (and those for whom grades are missing - possibly because courses were taken pass/fail) were less likely to persist. The information provided by freshman year grades about the likelihood of graduating is important to many students' subsequent enrollment decisions.

Institution-specific characteristics are generally not significantly associated with dropout rates for full-time students. Those attending a two-year institution were more likely to drop out than those attending a four-year institution. This may reflect the role of two-year institutions as trial institutions for full-time students. Distance from home may be positively associated with the costs of enrollment, but had no significant association with the decision to drop out. Even social and academic integration measures that might reflect new information about the ability of the respondent to adapt to the academic environment were not significant predictors of attrition. 
Amongst the economic indicators of cost, several are significantly associated with attrition. Full-time students living in an area with a higher unemployment rate were less likely to drop out than full-time students living in an area with a lower unemployment rate. ${ }^{3}$ This finding suggests that the students consider the market-based opportunity costs of enrollment when deciding whether to pursue a degree. We also estimated specifications controlling for the tuition rate at the first institution attended, but did not find this cost measure to be significantly associated with attrition.

Finally, we obtained some interesting findings on the role of financial aid in persistence for full-time students. Those receiving a grant were less likely to withdraw; those receiving a loan were more likely to withdraw - though neither of these effects is statistically significant. However, those full-time entrants with work-study aid were significantly less likely to withdraw. Other authors (King 2002) have found similar results and suggested that this is because workstudy provides students both with financial help and with further contacts on campus, thus binding the student more closely to the school. Work study aid may integrate students more into campus life than other measures of integration. Most of our findings for full-time students are in line with those reported elsewhere in the literature.

\section{Attrition of Part-Time as Compared to Full-Time Students}

Considerably less attention has been devoted in prior attrition studies to part-time students. Since fewer students enroll part-time than full-time, sample sizes are smaller. However, part-time students still comprise a substantial portion of undergraduates. A smaller

\footnotetext{
${ }^{3}$ We checked to see if changes in the unemployment rate over time influenced attrition. They did not, perhaps because small changes are difficult to observe. We also interacted the unemployment rate with respondent gender and dependency status. The results indicated that the unemployment rate has a greater impact on attrition for men (women may be more involved in home than economic alternatives) and for dependents (as those who are independent may already have a job), but neither effect is statistically significant.
} 
sample size increases the standard errors associated with the parameters and makes it difficult to precisely estimate parameters. A small sample size alone should not bias the parameter estimates, but the presence of a single outlier may have a disproportionate impact in small samples, particularly for characteristics rarely seen. Finally, small samples reduce cell sizes and increase the likelihood of observing perfect collinearity. Such is the case here, for example, with respect to 'more integrated' individuals. Relatively few part-time respondents were 'more integrated' socially or academically compared to the base case. Furthermore, all of these more integrated students persisted. While this is roughly in line with expectations, the related coefficient estimates tend to go towards negative infinity because one only needs to know that these students were more integrated to identify their probability of dropping out. To determine the impact other factors have upon attrition, one must exclude these respondents from the sample when estimating the other parameters.

Our results suggest some substantial differences in the factors influencing attrition for part-time as opposed to full-time students. First, while parental education is still significantly related to attrition for part-time students (p-value 0.05), its importance is much smaller than it is for full-time students. Part-time students may be less dependent upon their parents for financial or emotional support than full-time students. Second, we find that the timing of entry into college is not a significant predictor of attrition for part-time students. Neither gender nor age is a statistically significant determinate of attrition (p-value 0.50). Similarly, the term in which individuals initially matriculated and enrollment timing relative to high school completion are also not significant predictors of attrition for part-time students (p-value 0.84 ). Third, there is some evidence that household characteristics such as women's marital status and men's marital changes have a significantly different effect for full-time as opposed to part-time students. 
Generally, marriage-related factors are much less closely associated with attrition for part-time as compared to full-time students (indeed a test of all the marital status variables indicates that they are significant at only the $17 \%$ level). It may be that considerations of the household opportunity cost of time are taken into account in the enrollment intensity decision and are thus less important determinates of attrition.

Fourth, academic performance as measured by grades is substantially less important for part-time as compared to full-time students in predicting attrition. Indeed, grades as a whole are not significant determinants of attrition for part-time students (p-value 0.37), though part-time students with high grades were, like full-time students, more likely to persist. It is low grades that have a significantly lower association with dropout behavior for part-time students as compared to full-time students. Fifth, the unemployment rate is found to be positively but not significantly correlated with attrition for part-time students. This differs substantially from the negative relation found for full-time students and may be attributable to the fact that part-time students are often already employed either full-time or part-time and so less concerned about the ability to find employment should they drop out.

Some institutional factors are found to have a significantly different relation to attrition for part-time students as compared to full-time students, but we feel these results should be interpreted with caution given the small number of individuals with the characteristics of concern. For example, living a long way from school significantly reduced the probability of withdrawal for part-time students but not for full-time students. However, relatively few parttime students traveled a long distance to attend college. We also find some evidence that race and ethnicity are more significant determinants of attrition for part-time students. Hispanics and non-Black/non-white individuals enrolled part-time are significantly more likely to drop out. 
These factors are not found to be significant correlates for the full-time sample - though the direction of the effect is similar and the magnitude not statistically significantly different.

\section{Summary of Results}

Overall, our results confirm that while the unobservable factors associated with initial enrollment intensity are not related to the subsequent attrition decision, the observable factors associated with dropout behavior differ by initial enrollment intensity. While parental education, the timing of enrollment, college GPA, and the local unemployment rate are significantly associated with attrition for full-time students, they do not appear to be as significant for parttime students. There is some evidence as well, that marital and parental status are less related and racial/ethnic characteristics more related to attrition for part-time students. These differences are not attributable to the higher standard errors associated with smaller sample sizes, but are real differences observable in the magnitude of the odds ratios associated with each variable. However, once these underlying differences in observables are taken into account, there is no significant difference between the attrition probability of full-time and part-time students. In a pooled sample in which $\beta_{\mathrm{F}}$ is allowed to differ from $\beta_{\mathrm{P}}$, the coefficient for the dummy variable identifying part-time students is not a statistically significant predictor of attrition. Thus, it is not part-time enrollment per se that is correlated with attrition; rather it is underlying differences in observable factors between the two groups that leads to the correlation with attrition.

Furthermore, the full-time enrollment attrition model (equation C2) does a substantially worse job at identifying at-risk part-time students than the part-time enrollment attrition model (equation C3). While some of this differential is inherent in the fact that the part-time parameters were estimated off the part-time sample, the magnitude of the differential is 
substantial enough to warrant attention. Using a $50 \%$ cutoff rate such that any respondent predicted to drop out with a greater than 50\% probability is classified as at high risk for attrition, the part-time attrition model accurately identifies $52.3 \%$ of those who do drop out and $87.2 \%$ of those who do not drop out. By contrast, the full-time attrition model only accurately identifies $21.9 \%$ of those dropping out and $82.5 \%$ of those not dropping out. Thus, the full-time attrition model identifies fewer than half as many at-risk part-time students as the part-time attrition model and falsely draws attention to significantly more of those who are not at risk.

\section{IMPLICATIONS AND POSSIBLE EXTENSIONS}

Our results have several important policy implications. The first implication is that defining attrition over a longer time period and over higher education in general reveals a substantially lower attrition rate than point-in-time, institution-specific data show. If the goal of society is to have individuals successfully complete a post-secondary degree, then longitudinal, cross-institutional data are critical to the proper evaluation of retention/attrition rates. This point recognizes that a significant fraction of students actually stop out for one or several terms and some transfer between institutions. We find that our measured long-term dropout rate from higher education is only about half as large as the point-in-time, institution-specific measure.

The definition of attrition is important, given the increased efforts to hold colleges and universities accountable for student success. Colleges are now required to report their six year graduation rates and one year retention rates for full-time students. One year retention rates treat all students not enrolled at the institution to which they initially matriculated in the fall of their second year as being dropouts and hence "failures” from the educational system. Our results indicate that many of those students either return to that institution or transfer to another 
institution. Thus, a more useful measure of accountability for the US higher education system would be student rather than institution-based. Further, given the substantial enrollment of parttime students, some evaluation of how part-time students are fairing in the current system is also warranted. Those policy makers at state or national levels who want to better evaluate and fund institutions, may want to consider enrollment intensities when comparing institutions and developing state budget plans. An institution with almost all full-time residential students needs to be evaluated on a different scale than an institution with a large percentage of part-time students. We document a $13 \%$ first year long-term dropout rate for students initially enrolled full-time and a 37\% rate for students initially enrolled part-time in the 1989-90 academic year. These raw numbers seem to suggest that part-time enrollment is a serious risk factor for attrition. However, a second major implication of our analysis is that these substantially different dropout rates are due to differences in the underlying factors that affect the behavior of the two groups, rather than to enrollment intensity per se. Thus, it is not sufficient to include only a dummy variable to identify initial enrollment intensity in standard attrition models. Rather empirical work needs to permit the effect of covariates to differ by initial enrollment intensity. This finding suggests that similar analysis of attrition conditioning on other earlier decision outcomes, such as the decision to attend a two-year versus four-year institution, the decision to attend a local versus distant institution, and the decision to enroll immediately after high school versus delay matriculation, may also be beneficial and thus merits further research.

A third major contribution of this research, especially for institutional researchers, is the methodology we propose for analyzing enrollment patterns to better identify at-risk students, both full-time and part-time. A sequential choice model could be used at a local level by institutional researchers to examine attrition patterns within their own institution. This approach 
allows for the possibility of correlation between sequential decisions and lends itself to the segmenting of student populations by a variety of characteristics: part-time/full-time, instate/out-of-state, immediate or delayed matriculation. Any patterns that are observed could be used to (1) help identify students at-risk of dropping out, (2) focus counseling efforts, and (3) improve retention rates. Our results suggest that using a sample of only full-time students to construct an attrition model that is used to identify at-risk students of all types may waste significant resources both by failing to identify those truly at-risk and by targeting many more of those not at-risk. Separate analysis of entering populations by initial enrollment status may significantly improve this targeting and suggest policies to improve retention within each entering population.

While our analysis identifies clear differences between the determinants of attrition for full-time and part-time students, there remain a variety of empirical issues we did not address that provide fertile grounds for future research. For example, it seems likely that first year GPA provides less reliable information to individuals enrolled part-time than to individuals enrolled full-time regarding the probability with which they will complete a degree. Part-time students will necessarily attempt fewer courses than full-time students and so will logically perceive their grades to provide less information. Additional research controlling for the number of credits attempted and/or completed could better establish the importance of first year grades as a signal.

In addition, we find that students who are likely to have higher opportunity costs (such as older students and those with families of their own) are more likely to persist if enrolled parttime rather than full-time. This suggests that students enrolled part-time may have rationally chosen to enroll part-time and planned to take longer to graduate, in order to accommodate their life-cycle concerns. Part-time enrollment may have the advantage of a more flexible schedule to 
accommodate other activities, such as work and/or family responsibilities. Further information on how students spend their time and the cost of alternative services like childcare could shed further light on why attrition is lower for older persons, married persons, and parents who enroll part-time than it is for similar persons who enroll full-time. Given the increased attention paid to lifetime learning and adult education, such research could help institutions better counsel students with substantial nonacademic commitments.

We find different attrition patterns for part-time relative to full-time students. However, our study defines full-time/part-time status based only on first term intensity. Enrollment intensity may change over time and further research is necessary to reveal how changes in such status (whether self-initiated or recommended by counselors) will affect enrollment outcomes. More research is also necessary to examine the role of enrollment intensity as a factor influencing the likelihood of degree attainment and time-to-degree, as well as its impact on institutional costs. A comparison of results between the 1990/94 BPS and the more recent 19962001 Beginning Post-Secondary Survey would also be a valuable extension.

\section{CONCLUSION}

Using panel data from the 1990/94 BPS on individuals pursuing an academic degree, we estimate a two stage sequential decision model to determine the impact personal, household, academic, institutional, and economic factors have on long-term dropout behavior separately for those students who initially enrolled full-time and for those students who initially enrolled parttime. We find no evidence that the unobservable factors influencing initial enrollment intensity also influence the later attrition decision. Thus, the initial enrollment intensity decision need not be modeled jointly with the attrition decision. This result may be due to the rich set of covariates 
for which we are able to control; other researchers may find different results. However, we find substantial evidence to support our hypothesis that the observable factors related to attrition differ for full-time and part-time students and that a two equation attrition model that allows the coefficients, the reactions of students, to differ by initial enrollment intensity more accurately predicts long-term attrition. Specifically, the impacts of parental education, of the timing of matriculation, of first year GPA, of marital and parental status, and of the local unemployment rate are much greater for full-time than for part-time students. Race and ethnicity, by contrast, while not important for full-time students, appear to be correlated with attrition for those initially enrolled on a part-time basis.

Given our finding that full-time and part-time students with the same characteristics drop out at different rates, policy makers interested in promoting higher education will need to clearly distinguish between these two populations. Institutions seeking to identify students at-risk for dropping out will certainly need to condition their analysis on decisions made at the time of matriculation. Our results suggest that individuals with a high opportunity cost of time are more likely to enroll part-time and, perhaps surprisingly, are more persistent when enrolled part-time. Given the substantial number of students enrolled on a part-time basis and the results of our analysis, treating students as a homogeneous population, irrespective of their initial enrollment status, may not be in the best interest of the students, the institutions, or society as it seeks to encourage persistence toward graduation. 


\section{References}

Adelman, C. (1999). Answers in the Tool Box: Academic Intensity, Attendance Patterns, and Bachelor's Degree Attainment. Washington, D.C.: U.S. Department of Education.

Altonji, J. G. (1993). The Demand for and Return to Education When Education Outcomes are Uncertain. Journal of Labor Economics 11(1): 48-83.

Bean, J. P. (1980). Dropouts and Turnover. The Synthesis and Test of a Causal Model of Student Attrition. Research in Higher Education 12 (2): 155-87.

Bean, J. P. \& Metzner, B. S. (1985). A Conceptual Model of Nontraditional Student Attrition. Review of Educational Research 55(4): 485-540.

Becker, G. (1964). Human Capital. New York: National Bureau of Economic Research.

Bradburn, E. M. (2002). Short-Term Enrollment in Postsecondary Education.

Washington DC: U.S. Department of Education (NCES 2003-153).

Cabrera, A. F., Nora, A., \& Castañeda, M. B. (1993). College Persistence: Structural Equations Modeling Test of an Integrated Model of Student Retention. Journal of Higher Education 64(2): 123-139.

DesJardins, S. L., Ahlburg, D. A., \& McCall. B. P. (2002). A Temporal Investigation of Factors Related to Timely Degree Completion. The Journal of Higher Education 73(5): 555582.

DesJardins, S. L., Ahlburg, D. A., \& McCall, B. P. (1999). An Event History Model of Student Departure. Economics of Education Review 18: 375-390.

DesJardins, S. L., McCall, B. P., Ahlburg, D. A., \& Moye, M. J. (2002). Adding a Timing Light to the “Toolbox”. Research in Higher Education 43(1): 83-114. 
Harmston, M. T. (2004). Cross-Validation of Persistence Models for Incoming

Freshmen. AIR Professional File 93 (Fall).

Hoenack, S. \& Weiler, W. (1975). Cost-Related Tuition Policies and University

Enrollments. Journal of Human Resources 10(3): 332-360.

Horn, L. (1998). Stopouts or Stayouts? Undergraduates Who Leave College in Their

First Year. Washington DC: U.S. Department of Education (NCES 1999-087).

Horn, L. \& Berger, R. (2004). College Persistence on the Rise?: Changes in 5-Year

Degree Completion and Postsecondary Persistence Rates Between 1994 and 2000. Washington

DC: U.S. Department of Education (NCES 2005-156).

Ishitani, T. T. (2003). A Longitudinal Approach to Assessing Attrition Behavior Among

First-Generation Students: Time-Varying Effects of Pre-College Characteristics. Research in

Higher Education 44(4): 433-449.

Ishitani, T. T. \& DesJardins, S. L. (2002-2003). A Longitudinal Investigation of

Dropout from College in the United States. Journal of College Student Retention 4(2): 173-201.

King, J. E. (2002). Critical Choices How Students’ Financial Decisions Affect Their

Academic Success. 2002 ACE Policy Analysis.

Light, A. (1996). Hazard Model Estimates of the Decision to Reenroll in School.

Labour Economics 2: 381-406.

Maddala, G. S. (1989). Limited-Dependent and Qualitative Variables in Econometrics.

New York: Cambridge University Press.

Montmarquette, C., Mahseredjian, S., \& Houle, R. (2001). The Determinants of

University Dropouts: A Bivariate Probability Model with Sample Selection. Economics of

Education Review 20: 475-484. 
Murtaugh, P. A., Burns, L. D., \& Schuster, J. (1999). Predicting the Retention of University Students. Research in Higher Education 40(3): 355-371.

National Center for Higher Education Management Systems. (2005, November 15).

http://www.higheredinfo.org/dbrowser/index.php?year=2000\&level=nation\&mode=data\&state= $\underline{0 \& \text { submeasure }=119 .}$.

Nora, A. (1987). Determinants of Retention Among Chicano College Residents: A Structural Model. Research in Higher Education 26(1): 31-59.

O’Toole, D. M., Stratton, L. S., \& Wetzel, J. N. (2003). A Longitudinal Analysis of the Frequency of Part-Time Enrollment and the Persistence of Students Who Enroll Part-Time. Research in Higher Education 44(5): 519-537.

St. John, E. P., Hu, S., \& Weber, J. (2001). State Policy on the Affordability of Public Higher Education: The Influence of State Grants on Persistence in Indiana. Research in Higher Education 42(4): 401-428.

St. John, E. P. \& Starkey. J. (1995). An Alternative to Net Price Assessing the Influence of Prices and Subsidies on Within-Year Persistence. Journal of Higher Education 66(2): 156186.

Starkey, J. B. (1994). The Influence of Prices and Price Subsidies on the Within-Year Persistence by Part-time Undergraduate Students: A Sequential Analysis. Ph.D. diss., University of New Orleans.

Stratton, L. S., O’Toole, D. M., \& Wetzel, J. N. (2004). Factors Affecting Initial Enrollment Intensity: Part-Time versus Full-Time Enrollment. Economics of Education Review 23(2): 167-175. 
Stratton, L. S., O’Toole, D. M., \& Wetzel, J. N. (2005). A Multinomial Logit Model of College Stopout and Dropout Behavior. IZA Working Paper \#1634.

Thomas, S. L. \& Heck, R. H. (2001). Analysis of large-scale secondary data in higher education research: potential perils associated with complex sampling designs. Research in Higher Education 42(5): 517-540.

Thomas, S. L. \& Zhang, L. (2005). Post-Baccalaureate Wage Growth Within 4 Years of Graduation: The Effects of College Quality and College Major. Research in Higher Education 46(4): 437-459.

Tinto, V. (1975). Dropout from Higher Education: A Theoretical Synthesis of Recent Research. Review of Educational Research 45(1): 89-125. - (1988). Stages of Student Departure: Reflections on the Longitudinal Character of Student Leaving. Journal of Higher Education 59(4): 439-455. . (1993). Leaving College: Rethinking the Causes and Cures of Student Attrition (2nd ed.). Chicago: University of Chicago Press.

Weiler, W. C. \& Pierro, D. J. (1988). Selection Bias and the Analysis of Persistence of Part-time Undergraduate Students. Research in Higher Education 29(3): 261-272. 
Table 1

Sample Statistics for those Persisting and Dropping Out By Initial Enrollment Status

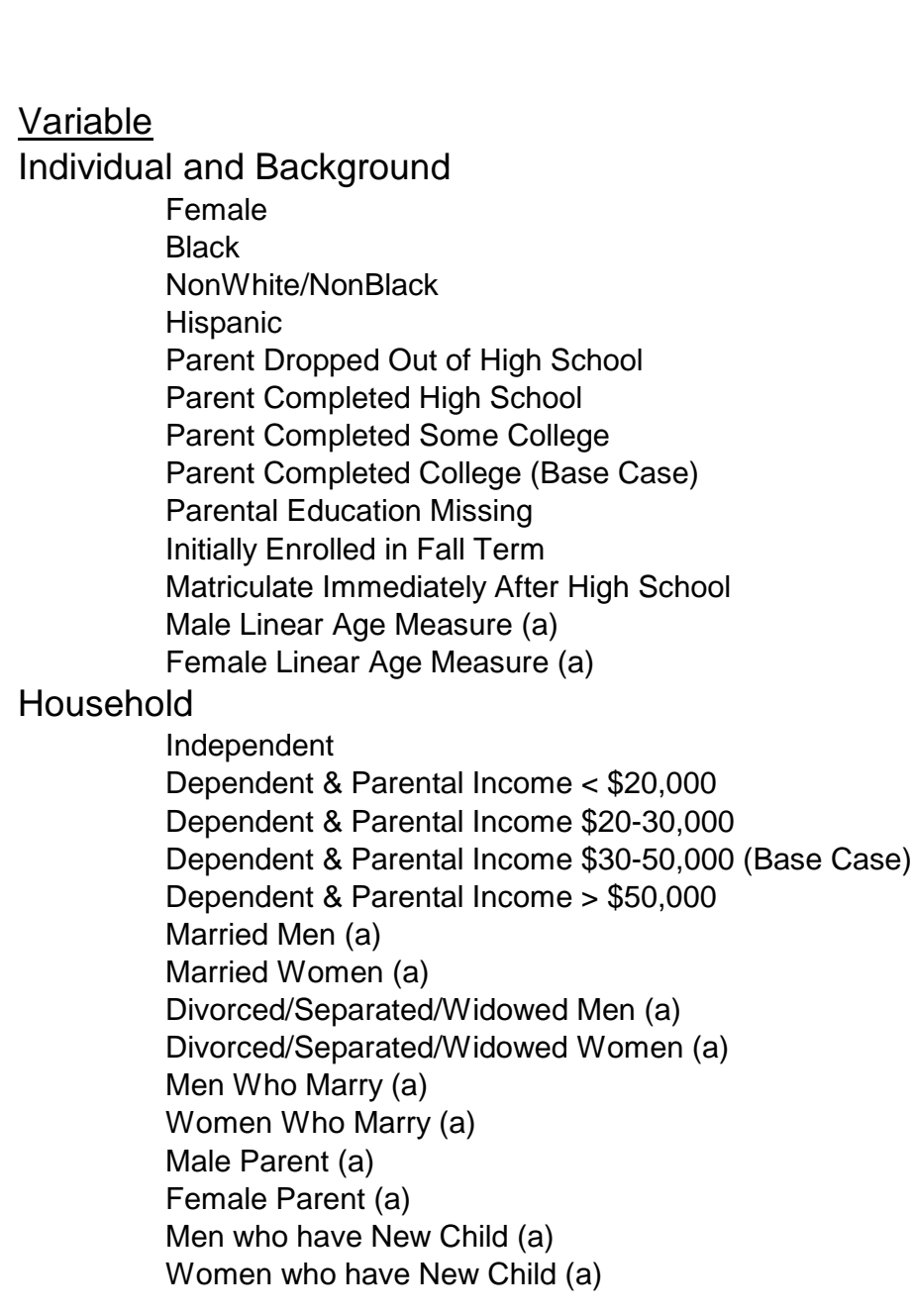

\section{Initially Enrolled Full-Time} Dropping

\section{Persisting}

$52.92 \%$

$7.60 \%$

$6.04 \%$

$5.29 \%$

$3.57 \%$

$25.28 \%$

$20.60 \%$

$49.70 \%$

$0.85 \%$

$97.56 \%$

$91.60 \%$

18.58

18.68

$6.01 \%$

$16.70 \%$

$25.97 \%$

$26.69 \%$

$24.63 \%$

$1.69 \%$

$2.43 \%$

$0.11 \%$

$0.87 \%$

$0.60 \%$

$1.50 \%$

$1.47 \%$

$3.54 \%$

$1.04 \%$

$1.36 \%$
Out

$54.72 \%$
$13.32 \%$
$3.39 \%$
$5.33 \%$
$8.47 \%$
$39.23 \%$
$22.28 \%$
$26.15 \%$
$3.87 \%$
$90.56 \%$
$69.49 \%$
20.08 **
20.46

$22.52 \%$ **

$18.89 \%$

$22.76 \%$

$15.25 \%$

$20.58 \%$

$3.21 \%$

$9.29 \%$

$1.60 \%$

$7.52 \%$ *

$3.74 \%$

$8.41 \%$ *

$4.28 \%$

$17.70 \%$

$2.14 \%$

$8.85 \%$ *
Initially Enrolled Part-Time

Dropping

Persisting

Out

FT vs.

$60.37 \%$

$8.29 \%$

$5.07 \%$

$12.90 \%$

$7.83 \%$

$41.01 \%$

$22.58 \%$

$22.12 \%$

$6.45 \%$

$82.95 \%$

$37.33 \%$

21.95

26.02

$49.77 \%$

$11.06 \%$

$12.90 \%$

$9.68 \%$

$16.59 \%$

$17.44 \%$

$35.11 \%$

$1.16 \%$

$10.69 \%$

$2.33 \%$

$1.53 \%$

$9.30 \%$

$35.88 \%$

$3.49 \%$

$2.29 \%$
$59.09 \%$

$12.88 \%$

$2.27 \%$

$7.58 \%$

$14.39 \%$

$39.39 \%$

$17.42 \%$

$18.94 \%$

$9.85 \%$

$81.06 \%$

$28.79 \%$

24.76

26.76

$58.33 \%$

$10.61 \%$

$15.15 \%$

$6.82 \%$

$9.09 \%$

$24.07 \%$

$35.90 \%$

$9.26 \%$

$16.67 \%$

$1.85 \%$

$2.56 \%$

$22.22 \%$

$43.59 \%$

$3.70 \%$

$8.97 \%$
$\mathrm{PT}$

\#

\#\#

\#\#

\#\#

\#\#

\#\#

\#\#

\#\#

\#\#

\#\#

\#\#

\#\#

\#\#

\#\#

\#\#

\#\#

\#\#

\#

\#\#

\#\#

\#\#

\# 
Academic Performance

Low Grade

Self-Reported Average Grade

Institution-Reported Average Grade (Base Case)

High Grade

Institutional

Missing Institution and Self-Reported GPA

Public Institution

Two Year Institution

Live within 10 miles of Insitution

Live further than 100 miles from Institution

More Academically Integrated

Less Academically Integrated

More Socially Integrated

Less Socially Integrated

\section{Economic}

Unemployment Rate in State of Residence

Expected Earnings (in thousands \$)

Received a Grant

Received a Loan

Received Work Study

Received Employer Provided Aid

Received Other Aid

Number of Observations

Sample Probability by Initial Enrollment Intensity

$$
\begin{aligned}
& \text { Unweighted } \\
& \text { Weighted }
\end{aligned}
$$

Weighted Total Sample Probability

$16.08 \%$
$8.07 \%$
$40.30 \%$
$34.63 \%$
$0.92 \%$

$38.26 \% \quad * *$

\section{$16.59 \%$}

$10.60 \%$

$30.99 \% \quad * * \quad 29.95 \%$

$17.43 \% \quad * * \quad 41.94 \%$

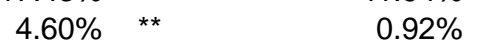

$18.18 \%$

$30.30 \%$

$34.85 \%$

$5.30 \%$ *

$43.69 \%$

$14.77 \%$

$17.62 \%$

$41.97 \%$

$12.36 \%$

$2.49 \%$

$8.58 \%$

$2.95 \%$

$56.17 \%$
$40.44 \%$
$27.60 \%$
$24.21 \%$
$7.99 \%$
$4.60 \%$
$2.66 \%$
$7.02 \%$

$70.97 \%$

$56.68 \%$

$48.39 \%$

$6.91 \%$

$6.91 \%$

$12.44 \%$

$0.92 \%$

$29.49 \%$

$66.67 \%$

$63.64 \%$

$51.52 \%$

$1.52 \%$ *

$0.00 \%$ **

$17.42 \%$

$0.00 \%$

$30.30 \%$

5.08
16.427
$22.58 \%$
$10.14 \%$
$0.92 \%$
$7.37 \%$
$6.91 \%$

5.21

17.065

$25.76 \%$

$7.58 \%$

$2.27 \%$

$7.58 \%$

$5.30 \%$

14.898

33.32\%

$15.39 \%$

$0.69 \%$

$10.17 \%$

$0.97 \%$

$6.91 \%$

132

$0.41 \%$

413

217

$37.82 \%$

$9.59 \%$

$62.18 \%$

$62.92 \%$

$37.08 \%$

$87.24 \%$

$10.47 \%$

$11.27 \%$

$6.64 \%$

(a) Identifies variables for which gender specific means are calculated.

${ }^{*}\left({ }^{*}\right)$ Indicates that means for those persisting are significant different at the $5 \%(1 \%)$ level from means for those dropping out.

\# (\#\#) Indicates that means for those initially enrolled part-time are significantly different at the $5 \%$ (1\%) level from means for those initially enrolled full-time. 


\section{Table 2 Logit Model of Attrition As a Function of Initial Enrollment Status}

$\underline{\text { Variables }}$ Initially Enrolled Part-Time

Individual \& Background:

Female

Black

NonWhite/NonBlack

Hispanic

Parent Dropped Out of High School

Parent Completed High School

Parent Completed Some College

Parental Education Missing

Initially Enrolled in Fall Term

Immediate Matriculation

Male Linear Age Effect

Female Linear Age Effect

Household:

Independent

Dep. \& Income $<\$ 20,000$

Dep. \& Income $\$ 20-30,000$

Dep. \& Income $>\$ 50,000$

Married Men

Married Women

Div/Sep/Wid Men

Div/Sep/Wid Women

Men Who Marry

Women Who Marry

Male Parent

Female Parent

Men who have New Child

Women who have New Child

$\begin{array}{cc}\text { Those Initially } & \text { Those Initially } \\ \text { Enrolled Full-Time } & \text { Enrolled Part-Time }\end{array}$

FT

PT

Difference Between

Odds Ratios

Odds Ratios

$\underline{\text { FT \& PT }}$

19.3805

(0.0020)

1.2202

(0.5050)

0.5429

$(0.2500)$

0.9918

(0.9860)

2.2121

(0.0550)

2.2050

(0.0010)

1.9737

(0.0050)

2.9739

(0.0460)

0.3944

(0.0020)

0.3522

(0.0000)

1.1038

(0.0830)

0.9232

(0.0400)

0.2844

(0.3720)

2.0431

(0.3710)

0.1145

(0.0290)

0.3899

(0.0920)

4.1083

(0.0550)

1.1491

(0.8190)

0.6154

(0.4230)

2.7943

(0.2420)

1.2490

(0.5640)

0.9083

(0.8520)

1.0199

(0.8080)

1.0660

(0.1800)

1.0937

1.4916

(0.8250)

1.8439

(0.0660)

1.1253

(0.6920)

1.5258

(0.1110)

0.2859

(0.4300)

1.9308

(0.2770)

4.5420

(0.2340)

3.8835

(0.1560)

9.3725

(0.0000)

2.8010

(0.0720)

0.5710

(0.4270)

5.5750

(0.0010)

1.6304

(0.7350)

3.9247

(0.0170)
(0.7010)

1.4227

(0.6890)

3.9977

(0.1160)

1.2728

(0.7980)

2.4002

(0.3780)

0.2087

(0.1420)

4.4342

(0.3380)

1.0341

(0.9760)

0.1990

(0.2460)

0.8808

(0.9210)

1.8200

(0.5670)

1.7109

(0.4940)

0.2137

(0.1900)

8.4904

(0.1020) 
Academic Performance:

Low Grade

3.2647

1.0004

(0.0000)

(0.9990)

Self-Reported Average Grade

1.6980

0.6313

(0.0940)

(0.5010)

High Grade

0.5194

0.5721

(0.0090)

(0.1500)

Missing All GPA Reports

3.3385

4.1506

(0.0980)

$(0.2120)$

Institutional:

Public Institution

1.0726

0.4851

Two Year Institution

(0.7080)

(0.1730)

2.1899

1.5800

(0.0000)

(0.3010)

Live within 10 miles

0.9850

0.9331

(0.9380)

(0.8320)

Live further than 100 miles

0.8347

$(0.3630)$

More Academically Integrated

0.6210

0.1152

(0.0400)

(0.1500)

Less Academically Integrated

1.1707

- infinity

$* * *$

More Socially Integrated

$(0.6390)$

0.7900

(0.6070)

Less Socially Integrated

0.7365

$(0.3540)$

1.8232

(0.2820)

- infinity

$\star \star *$

0.4277

(0.0270)

Economic:

Unemployment Rate

Expected Earnings (in 000s)

0.8569

(0.0470)

1.2878

0.9613

(0.1730)

(0.6650)

0.8878

Received a Grant

0.8630

(0.3630)

(0.5210)

0.8069

Received a Loan

1.3902

(0.6990)

1.0472

(0.1510)

(0.9570)

Received Work Study

0.5158

2.2333

(0.0590)

(0.5850)

Received Employer Provided Aid

0.8025

1.5682

(0.7840)

$(0.5630)$

Received Other Aid

0.9647

0.4240

(0.8940)

(0.2990)

Number of Observations

4,306

349

- infinity means the coefficient tends towards negative infinity because of perfect colinearity.

$\mathrm{P}$-Values are reported in parentheses below the coefficient values.

Asterisks indicate variables that have significantly different coefficient values for those initially enrolled full-time as compared to part-time. ${ }^{* \star *}$ indicates significance at the $1 \%$ level, ${ }^{* \star}$ at the $5 \%$ level, and * at the $10 \%$ level.

All statistics take into account the complex sample design of the BPS, taking into account the possibility that there could be a common error component for all institutions drawn from the same stratum and for all individuals drawn from a common institution. 